\title{
MATHEMATICAL MODELS OF TEMPERATURE IN ELECTRIC DISCHARGE ROLLING OF METALS
}

\author{
A. Yu. Albagachiev ${ }^{1}$, A. M. Keropyan ${ }^{2}$, A. A. Gerasimova ${ }^{2}$, A. N. Pashkov² \\ ${ }^{1}$ Mechanical Engineering Research Institute of the Russian Academy of Sciences - IMASH RAN (Moscow, Russia); \\ ${ }^{2}$ National University of Science and Technology “MISiS” (Moscow, Russia)
}

E-mail:albagachiev@yandex.ru; am_kerop@mail.ru;gerasimova.aa@misis.ru

\section{AUTHOR'S INFO \\ A. Yu. Albagachiev, Dr. Eng., Prof., Head of the "Friction, Wear, Lubrication. \\ Tribology" Dept. \\ A. M. Keropyan, Dr. Eng., Prof., Dept. of Engineering of Technological Equipment \\ A. A. Gerasimova, Cand. Eng., Associate \\ Prof., Dept. of Engineering of \\ Technological Equipment \\ A. N. Pashkov, Cand. Eng., Associate \\ Prof., Dept. of Engineering \\ of Technological Equipment}

Key words:

rolling, electric current, mathematical model, temperature, steel 3, VT-6 titanium alloy, slipping, bonding.

\begin{abstract}
A B S T R ACT
The model of analytical calculation of the average volumetric temperature of plastic deformation in the conditions of applied impulse current was developed on the base of rolling energy balance. Additionally, the formula for determination of the contact temperature between rolls and strip as well as temperature gradient through strip thickness and its variation in time of electroplastic process conduction was concluded on the base of solution of the heat conductivity differential equation in Fourier partial derivatives. This equation is valid for the boundary condition taking into account joint heating with impulse current and plastic deformation. Conducted temperature calculations for dimensionless time in the deformation area during electric discharge rolling of steel 3 and VT- 6 titanium alloy displayed that temperature rise up to its maximal value has temporal displacement to strip exit side of deformation area. It is connected with temporal retarding of heat forming comparing with the time of elastic-plastic deformation. As soon as the contact square of rolls with strip has two different areas, where bonding and slipping are realized via rolling friction and slipping friction, immediate temperatures will also differ respectively. The obtained models allow to conduct calculations of the contact temperatures in the areas of roll bonding and slipping relating to the rolling strip. Electric discharge rolling reduces conventional cold rolling technology via elimination of heating with intermediate heat treatment (annealing) and improves thereby thin strip quality via healing of its cracks and defects by electric impulses, as well as increases productivity by $30 \%$.
\end{abstract}

\section{Introduction}

Rolling of hard-to-deform metals is conducted with passing of impulse electric current of high density, and the following effects are observed in the rolling metal: temperature rise, pinch effect, skin effect etc. Despite of systematic researches that have been taken place in this direction for many decades, the common opinion about the effect of impulse current on the mechanisms of variation of temperature as well as parameters of strength and ductility of metals, creep and relaxation of mechanical stresses is absent [1-6]. Some researchers think that electroplastic effect is not connected with heating, but it is stipulated by direct influence of conductivity electrons on dislocations and other defects of crystal lattice and thereby provides prevailing influence on the processes in metal. It is suggested that the effect of electroplasticity is determined by essential local heterogeneity of temperature distribution through metal volume, i.e. it has thermal nature that is not examined yet [7-9]. The attempts of temperature measuring during experimental rolling of the spherical thermocouple head at the rolling mill in the RAS Institute of Machine Science were not successful due to time delay of this thermocouple. The temperature of plastic deformation during rolling can be measured with its help, but it is impossible during electric impulses with duration $100 \mu \mathrm{s}$.

To measure such temperature, the special low-inertial film thermocouple is under creation. Thereby development of mathematical model for theoretical evaluation of the temperature of electric discharge rolling seems to be rather actual.

\section{Materials and methods of the research}

During mechanical and electric discharge effects, heat is practically immediately generated in crystal cells of processing metal. Contradictory data on this problem are presented in different investigations [10-12].

The work [2] displays that the temperature during electric discharge rolling of metals (EDRM) makes only 300-350 K. The magma plasma model of cell deformation during contact interaction of two irregularities was firstly suggested by Thiesen [1] on the base of multiple conducted experiments (fig. 1). This model testifies about high contact temperature.

The authors think that such temperature, reaching plasma during short time of $10^{-9} \mathrm{~s}$ can be observed in microvolumes of crystal cells. Sharp rise of force (and, respectively, of power) in convergence of time (denominator) to zero in the Newton's dynamic mechanics can be considered as an additional prove confirming thermal physics of the examined model.

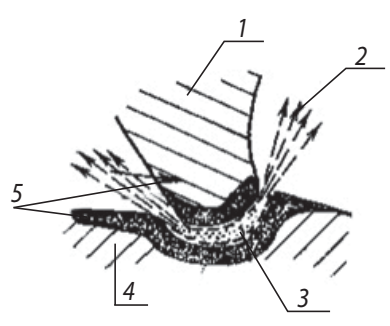

Fig. 1. Magma plasma model during plastic deformation [1]: 1-tool; 2 - atoms, electrons, photons; 3-plasma; 4 processing component; 5 - solid shell (structure that reduced after finish of dynamic effect) 


$$
P=\frac{m V}{t} \text {, when } t=10^{-7} \mathrm{~s} P=10^{7} \mathrm{mV} \text {. }
$$

Let's examine thermal physics of the process of combined rolling (fig. 2).

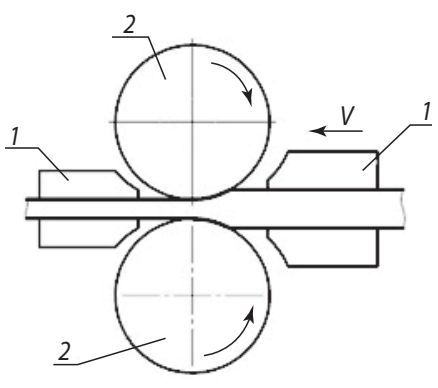

Kinetic energy of elastic-plastic deformation and heating by impulse current are the sources of contact heat forming during electric discharge rolling of metals. Depending on their value, the contact temperature can vary from the room temperature (at low energy values, small deformation rates and current density values) to the melting temperature (at large mechanical and electric energy values and high deformation rates). Owing to discreteness of contact square connected with roughness between roll and strip, it is necessary to differ average room temperature, volumetric and temperature flash. Total amount of heat generating during electric discharge rolling can be expressed as follows (taking into account the energy conservation law in plastic deformation and the Joule-Lenz's law for applied current impulses, as well as process symmetry):

$$
W=\left(P f V+\sum_{1}^{n} I U\right) t=Q,
$$

where $P$ - normal force, $f-$ friction ratio, $V-$ rate, $I$ - electric current, $U$ - voltage, $Q-$ heat amount, $W-$ work, $n$ - amount of applied current impulses during plastic deformation time $t=L / V(L-$ length of mechanical contact in rolling).

From the other side, this heat amount (the process is considered as adiabatic one) during contact time provides heating of volumes of rolls and rolled strip to the determined temperature

$$
Q=Q_{1}+Q_{2}=C_{1} \rho_{1} A b_{1} \theta_{1}+C_{2} \rho_{2} A b_{2} \theta_{2},
$$

where $C_{1}, C_{2}$ - specific heat conductivity of material (sample and anvil); $\rho_{1}, \rho_{2}$ - density of contacting bodies; $A$ - contact square; $b_{1}, b_{2}$ - efficient depth of heat impulse penetration; $\theta_{1}, \theta_{2}-$ average volumetric temperature of the first and second bodies.

$$
b_{1}=2 \sqrt{a_{1} t} ; \quad b_{2}=2 \sqrt{a_{2} t},
$$

where $a_{1}, a_{2}$ - temperature conductivity coefficients of roll and strip material.
To determine the distribution coefficient $\alpha$ of heat flows between rolled strip and rolls during electric discharge rolling, owing to short time of the process we can use F. Sharron's formula [10].

Substituting (2) and (3) in (1) and equalizing contact temperatures we get

$$
\theta=\frac{(1-\alpha)\left(P f V+\sum_{1}^{n} I U\right) \sqrt{t}}{2 A\left(\sqrt{\lambda_{1} c_{1} \rho_{1}}+\sqrt{\lambda_{2} c_{2} \rho_{1}}\right)} .
$$

The formula (4) is valid for approximate evaluation of the average temperature of rolled strip that will be heated during its processing; however, it can't provide to determine the temperature on the surface and at some distance from it at each temporal interval. Deformation source of heat is most completely characterized by power. Thereby let us consider the most general case when power is varying in time according to the parabolic law.

The power of plastic deformation at each temporal interval of the contact can be described by the following expression:

$$
N_{1}=\operatorname{Pf} V \frac{t}{\Delta t}\left(1-\frac{t}{\Delta t}\right),
$$

where $P, V-$ maximal contact force and rate respectively; $t$ - current time coordinate; $\Delta t$ - time of heat generating.

The power of rolled strip during the effect of $n$ current impulses is as follows:

$$
N_{2}=\sum_{1}^{n} I U \cdot \frac{t}{\Delta t}\left(1-\frac{t}{\Delta t}\right),
$$

Total rolling power is equals to

$$
N=N_{1}+N_{2}=\left(P V f+\sum_{1}^{n} I U\right) \frac{t}{\Delta t}\left(1-\frac{t}{\Delta t}\right) .
$$

Solving the task of heat forming and heat conductivity during electric discharge rolling is concluded to solving the Fourier differential equation of heat conductivity for linear heat flow.

$$
\frac{\partial \Theta}{\partial t}=a \frac{\partial^{2} \Theta}{\partial x} .
$$

With initial condition

$$
\Theta=0 \quad \text { at } t=0
$$

and boundary conditions

$$
-\lambda \frac{\partial \Theta}{\partial x}=\frac{(1-\alpha)\left(\left(P f V+\sum_{1}^{t} I U\right)\left(\frac{t}{\Delta t}-\frac{t^{2}}{\Delta t^{2}}\right)\right.}{A} ;
$$


$\Theta=0$ at $x \rightarrow \infty$.

The equation (8) can be solved via the method of Laplace integral transformation. Substituting the expressions for derivates in this equation we can go forward to the operator equation.

$$
S \Theta=a \frac{d^{2} \Theta}{d x^{2}} .
$$

Applying Laplace transformation to the boundary condition (10), we shall get corresponding equations:

$$
-\lambda \frac{d \Theta}{d x}=\frac{(1-\alpha)\left(P f V+\sum_{1}^{n} I U\right)}{A \Delta t}\left(\frac{1}{S^{2}}-\frac{2}{S^{3} \Delta t}\right) .
$$

General solution of differential equation (12) is as follows:

$$
\Theta(x, S)=C_{1} e^{X \sqrt{\frac{S}{a}}}+C_{2} e^{-X \sqrt{\frac{S}{a}}} .
$$

The arbitrary constants $C_{1}$ and $C_{2}$ are determined using the boundary conditions (11) and (13) and the following physical reason of the required task that the image is limited at $x \rightarrow \infty$. The last means that $C_{1}=0$.

\section{Results of the research}

After integration and transition from image to original using the convolution theorem we shall finally get

$$
\begin{aligned}
& \left\{\left(1-\frac{t}{\Delta t}\right) t\left[2 \sqrt{a t} \exp \left(-\frac{x}{4 a t}\right)-\sqrt{\pi} x \operatorname{erfc}\left(\frac{x}{2 \sqrt{a t}}\right)\right]-\frac{1}{2 a}\left(1-\frac{t}{\Delta t}\right) \times\right. \\
& \times\left[\frac{(2 \sqrt{a t})^{3} \exp \left(-\frac{x^{2}}{4 a t}\right)-4 x^{2} \exp \left(-\frac{x^{2}}{4 a t}\right) \sqrt{a t}}{3}+\frac{2}{3} x^{3} \sqrt{\pi} \operatorname{erfc} \frac{x}{2 \sqrt{a t}}\right]- \\
& \left.-\frac{1}{80 a^{2} \Delta t} \cdot\left[(2 \sqrt{a t})^{5} \exp \left(-\frac{x^{2}}{4 a t}\right)-\frac{2}{3} x^{2}(2 \sqrt{a t})^{3} \exp \left(-\frac{x^{2}}{4 a t}\right)+\right]\right\} \\
& \left.\left.+\frac{4}{3} x^{4} 2 \sqrt{a t} \exp \left(-\frac{x^{2}}{4 a t}\right)-\frac{4}{3} x^{5} \sqrt{\pi} \operatorname{erfc} \frac{x}{2 \sqrt{a t}}\right]\right\}
\end{aligned}
$$

The formula (15) allows to calculate the average temperature of contact surface and volumetric temperature at the each moment of friction time. If $x=0$ (in the contact between rolls and strip), the formula (15) can be expressed as

$$
\Theta(0, t)=\frac{4(1-\alpha)\left(\left(P f V+\sum_{1}^{n} I U\right) \sqrt{a t}\right)}{3 \sqrt{\pi} A \lambda}\left(\frac{t}{\Delta t}-0.8 \frac{t^{2}}{\Delta t^{2}}\right) .
$$

Two kinds of friction - slipping (at entry and exit of rolls) and bonding - appear during rolling in the area of plastic deformation between a roll and rolled strip. We don't know what effect has impulse current on contact slopping because such investigations were not conducted; they are planned for the future. But the authors can suggest their analytical models for temperature determination.

Based on the works [13-19], slipping occurs when shift value during plastic deformation reaches production of friction coefficient and pressure force, i.e.

$$
\tau=f P_{\text {pres }}=\frac{f p}{A} .
$$

Let us insert shift value in (16) and express it through force and square $\tau=f p / A$.

$$
\begin{aligned}
& \Theta(0, t)=\frac{0,424(1-\alpha)\left(\tau V+\sum_{1}^{n} \frac{I}{A} U\right) \sqrt{a t}}{\lambda} \times \\
& \times\left(\frac{t}{\Delta t}-0.8 \frac{t^{2}}{\Delta t^{2}}\right) .
\end{aligned}
$$

The curves of the contact temperature variation in time during electric discharge rolling of steel 3 and VT-6 titanium alloy were obtained using model (17) and are presented at the fig. 3 .
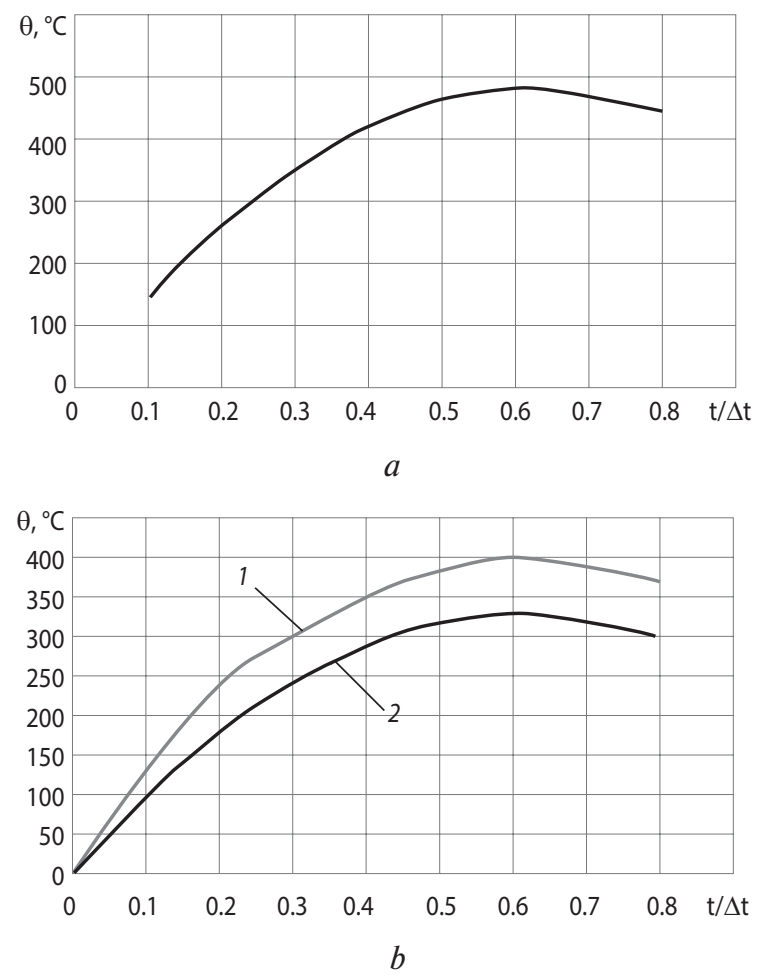

Fig. 3. Temperature variation in time in the deformation area: $a-$ at electric discharge rolling of steel 3

$\left(\tau=120 \mathrm{MPa}, V=5 \mathrm{~m} / \mathrm{s}, I=5 \cdot 10^{6} \mathrm{~A} / \mathrm{m}^{2}\right.$, $\lambda=41.9 \mathrm{~J} / \mathrm{m}$ with $\left.{ }^{\circ} \mathrm{C}\right) ; b-$ at cold rolling (1) and electric discharge rolling (2) of VT-6 alloy $\left(\tau=223 \mathrm{MPa}, V=0,05 \mathrm{~m} / \mathrm{s}, I=5 \cdot 10^{6} \mathrm{~A} / \mathrm{m}^{2}, U=5 \mathrm{~V}\right.$, $\lambda=12,75 \mathrm{~J} / \mathrm{m}$ with ${ }^{\circ} \mathrm{C}$ ) 
The curve presented on the fig. $3 a$ displays that the contact temperature in the deformation area increases in time and the maximal value at electric discharge rolling of steel 3 strip $\left(490{ }^{\circ} \mathrm{C}\right)$ is reached at $0,6 t / \Delta t$. The same type of increase of the maximal contact temperature up to $400{ }^{\circ} \mathrm{C}$ in time between the roll and rolled strip is observed during electric discharge rolling of VT-6 alloy (see fig. $3 b$ ). The cause of low values of calculated temperature can be identified as low rolling speed of VT-6 alloy, though its shift stresses are rather higher that these of steel 3. Temporal displacement of temperature rise up to its maximal value from the center to the exit of strip from the deformation area can be explained by temporal retard of heat forming during elastic-plastic deformation.

It should be noted that the contact square between the rolls and rolling strip includes two areas with different generating temperatures. It is the area of Coulomb friction $(\tau=f P / A)$ describing roll slipping relating to strip (examined in this work) and the area of bonding friction.

Bonding between the rolls and strip is observed during their contact, when current shift value reaches the permissible value of shifting tensile strength $\tau_{s}$. To determine the bonding temperature, we need to replace $\tau=\tau_{s}$ in the formula (17).

Thereby, the thermal physical models for determination of volumetric strip temperature, temperature in the contact area between the roll and strip as well as temperature in the area of slipping and bonding during electric discharge rolling were developed based on solution of Fourier parabolic equation of heat conductivity.

\section{Conclusions}

The contact temperature during electric discharge rolling can vary from room temperature (at low energy values, small deformation rates and small current density) to melting temperature (at high values of mechanical and electric energies and high deformation rates). It can be controlled during mechanical loading (plastic deformation) by standard sensors and measuring devices.

To measure the temperature at the current with duration of applied impulse $\mathrm{t}=10^{-5}-10^{-7} \mathrm{~s}$ in the laboratorial conditions, it is required to develop the fine technique using more perfect sensors, signal amplifier, controller, computer, having together summarized response speed by an order more than activity of applied impulse.

Summarized non-stationary temperature during electric discharge rolling can be determined via analytical method, using the models suggested in this work or using numerical experiment conducted via finite elements method.

Electric discharge rolling reduces the conventional cold rolling technology except one operation (heating in furnaces and intermediate heat treatment - annealing) and improves quality of thin strip due to healing of its cracks and defects by electric impulses, and also increases its productivity by $30 \%$. The annual economical efficiency after replacement of usual rolling mill by electric discharge one makes $10 \mathrm{mln}$ rubles [2].

\section{REFERENCES}

1. Thiesen P.A Physikalisch-chemische Untersuchungen tribomechnischer Vorgange. Zeitschrift Chemie. 1965, S. 162-171.

2. Troitskiy O. A., Baranov Yu. V., Avraamov Yu. S., Shlyapin A. D. Physical grounds and processing technologies for modern materials. 2 volumes. Vol. 1. Moscow - Izhevsk: Institut kompyuternykh issledovaniy. 2004. 590 p.

3. Fomin A. A., Gusev V. G., Timerbaev N. F. The processing of the profile surface of the work-pieces, characterized by low rigidity. Solid State Phenomena. 2020. 299 SSP. pp. 852-860.

4. Keropyan A., Gerasimova A., Goloshapov K. Influence of the track gradient on the contact temperature at the wheel-rail zone for open-pit locomotives. International Conference on Modern Trends in Manufacturing Technologies and Equipment (ICMTMTE 2017). MATEC Web of Conferences. 2017. 129, 06009.

5. Basyrov I. I., Bardovsky A. D. Innovative crushing technique and vertical roll crusher design. Gornyi informatsionno-analiticheskiy byulleten. 2020. No. 2. pp. 121-129.

6. Kolikov A. P., Romantsev B. A. Theory of metal forming. A manual. Moscow.: Izdatelskiy dom MISiS. 2015. 451 p.

7. Chitkara N. R., Aleem A. Axi-symmetric tube extrusion/piercing using die-mandrel combinations: some experiments and a generalised upper bound analysis. International Journal of Mechanical Sciences. 2001. No. 43. Iss. 7. pp. 1685-1709.

8. Tyurin V. A., Mokhov A. I. Theory of metal forming. A manual for high schools. Volgograd. VolgGTU. 2000. 416 p.

9. Artiukh V., Mazur V., Prakash R. Increasing hot rolling mass of steel sheet products. Solid State Phenomena. 2016. 871, pp. 3-8. DOI: 10.4028/www.scientific.net/MSF.871.

10. Albagachiev A. Yu., Keropyan A. M., Gerasimova A. A., Kobelev O. A. Determination of rational friction temperature in lengthwise rolling. CIS Iron and Steel Review. 2020. Vol. 19. pp. 33-36.

11. Keropyan A. M., Gerasimova A. A. Connection between the temperature in the contact area of the system "wheel - rail" with railway inclination for industrial railroad transport. Izvestiya vuzov. Chernaya metallurgiya. 2017. Vol. 60. No. 5. pp. 355-363. DOI: $10.17073 / 0368-0797-2017-5-355-363$

12. Chen H., Li F., Li J. Experimental study on pure titanium during the positive-torsion and positive-negative-torsion. Materials Science and Engineering: A. 2016. Vol. 674. pp. 552-568.

13. Fomin A. A., Gusev V. G. Safe machining of blanks with nonuniform properties. Russian Engineering Research. 2013. Vol. 33. No. 10. pp. 602-606. DOI: 10.3103/S1068798X13100043

14. Gerasimova A., Mishedchenko O., Devyatiarova V. Determination of temperature conditions for steel plate rolling at Vyksa Steel Works (AO VMZ). IOP Conf. Series: Materials Science and Engineering. 2020. 709. Iss. 1. 022016. DOI: 10.1088/1757899X/709/2/022016.

15. Kondratenko V. E., Devyatiarova V. V., Albul S. V., Valeeva L. M. Method of calculating volumetric scaffold of monolithic slab formwork. IOP Conf. Series: Materials Science and Engineering. 2020. 971. No. 052036. P. 32-35. DOI: 10.1088/1757899 X/971/5/052036.

16. Biasoli De Mello J. D., Binder C., Hammes G., Binder R., Klein A. N. Tribological behaviour of sintered iron based selflubricating composites. Friction. 2017. No. 5 (3). pp. 285-307.

17. Holmberg K., Kivikyto-Reponen P., Harkisaari P., Valtonen K., Erdemir A. Global energy consumption due to friction wear in the mining industry. Tribology International. 2017. No. 115. pp. 116-139.

18. Gorbatyuk S. M., Gerasimova A. A., Radyuk A. G. Using the Coating for the Diffusion Layer Obtaining on the Walls of the Mold (CCM). Metallurgical and mining industry. 2015. Iss. 9. pp. 1085-1088.

19. Artiukh, V., Mazur, V., Adamtsevich, A. Priority influence of horizontal forces at rolling on operation of main sheet rolling equipment. MATEC Web of Conferences. 2017. 106. Paper No. 04001. DOI: $10.1051 /$ matecconf/201710604001. 